WA Yta $x$

2. To: (Receiving Orgenzention)

Distribution

6. Proj./Prog./Dept./Div:

LDUA

8. Originator Aemurks:

Approval/Release
3. From: (Originating Organization)

Remote System and Sensor

Applications

6. Cog. Engr.:
A. F. Pardini

1. EDT

4. Releted EDT No.

7. Purhase Onder No: $N / A$

0. Equip./Component No.:

10. Syetom/Bidg. Focllity:

12. Major Aesm. Dwg. No.:

13. Pomit/Pormit Application No.:

14. Raqubred Rospones Date:

16.

\begin{tabular}{|c|c|c|c|}
\hline $\begin{array}{l}\text { (A) } \\
\text { ltem } \\
\text { No. }\end{array}$ & (B) Document/Drawing No. & $\begin{array}{l}\text { (C) Shoet } \\
\text { No. }\end{array}$ & $\begin{array}{l}\text { (D) Rov. } \\
\text { No. }\end{array}$ \\
\hline 1 & WHC-SD-TD-TRP-006 & Al1 & 0 \\
\hline & & & \\
\hline & & & \\
\hline & & & \\
\hline & & & \\
\hline & & & \\
\hline & & & \\
\hline & & & \\
\hline
\end{tabular}

16.

Approval Designator [F]

E, S. Q. D OR N/A (S.0 WHC-CM-3-5, Sec. 12.7

\begin{tabular}{|c|c|c|}
\hline (G) & (H) & 17. \\
\hline $\begin{array}{l}\text { Res } \\
\text { son }\end{array}$ & Diep. & [J] Name \\
\hline 1 & & Coo. Eng.AF Pardi \\
\hline 1 & 1 & cos. Mor.DS Dutt \\
\hline & & $\mathbf{a A}$ \\
\hline & & Safaty \\
\hline & & Env. \\
\hline 1 & & KL Bennett \\
\hline $\begin{array}{l}\text { Stphat } \\
\text { Origin }\end{array}$ & of $\mathrm{E}$ & 2disen $5 / 6 / 94$ \\
\hline
\end{tabular}

(K) signeture

\section{DATA TRANSMITTED}

(E) Tithe or Deseription of Dote Tranemitted

Post Delivery Test Report for the Light Duty Utility Arm High Resolution Stereoscopic Video Camera System (HRSVS)

\begin{tabular}{|c|c|c|c|}
\hline (F) & (6) & (M) & (I) \\
\hline $\begin{array}{l}\text { Approvel } \\
\text { Desle- } \\
\text { netor }\end{array}$ & $\begin{array}{c}\text { Raseon } \\
\text { for Trane- } \\
\text { mittel }\end{array}$ & $\begin{array}{l}\text { Origt } \\
\text { nator } \\
\text { Diepo- } \\
\text { stion }\end{array}$ & $\begin{array}{l}\text { Receiv- } \\
\text { or } \\
\text { Dinpo } \\
\text { sition }\end{array}$ \\
\hline$N / A$ & $1 / 2$ & 7 & \\
\hline & & & \\
\hline & & & \\
\hline & & & \\
\hline & & & \\
\hline & & & \\
\hline & & & \\
\hline & & & \\
\hline
\end{tabular}

KEY

\begin{tabular}{|c|c|}
\hline & oasen for Transmittal (G) \\
\hline $\begin{array}{l}\text { 1. Approval } \\
\text { 2. Reloese } \\
\text { 3. Information }\end{array}$ & $\begin{array}{l}\text { 4. Roviow } \\
\text { 5. Post-Roview } \\
\text { 6. Dint. (Rioceipt Ariknow. Required) }\end{array}$ \\
\hline
\end{tabular}

$$
\text { (2. }
$$

SIGNA TURE/OISTRIBUTION

(See Approval Decionator for required elonetureel

1. Approwed

2. Approved wicomment

3. Ditapproved w/commont
Dispostition (H) 1 (II)

4. Aoviewed no/eomment

5. Aoviowed wioomment

B. Receipt ecknowlodoed

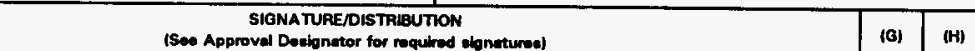
\begin{tabular}{ll|l} 
(L) Date (M) MSiN & (J) Name
\end{tabular}

(K) Signeture

(L) Date

(M) MSIN $\begin{gathered}\text { Aas- } \\ \text { won }\end{gathered}$ 


\section{Post Delivery Test Report for the Light Duty Utility Arm High Resolution Stereoscopic Video Camera System (HRSVS)}

Allan F. Pardini

Westinghouse Hanford Company, Richland, WA 99352

U.S. Department of Energy Contract DE-AC06-87RL10930

$\begin{array}{lll}\text { EDT/ECN: } 701455 & \text { UC: } 2060 \mathrm{~N} \\ \text { Org Code: } 8 A 800 & \text { Charge Code: HIEOl } \\ \text { B\&R Code: } & \text { EW } 4010000_{k N} & \text { Total Pages: } 40\end{array}$

Key Words: LDUA, High Resolution Stereoscopic Video Camera System (HRSVS), common video end effector (CVEE), Labview, Nondestructive Examination

Abstract: This report documents the post delivery testing of the High Resolution Stereoscopic Video Camera System (HRSVS) LDUA system, designed for use by the Light Duty Utility Arm (LDUA) project. The post delivery test shows by demonstration that the high resolution stereoscopic video camera system is fully operational to perform the task of aligning the LDUA arm and mast with the entry riser during deployment operations within a Hanford Site waste tank.

TRADEKARK DISCLAIMER. Reference herein to any specific commercial product, process, or service by trade nane, tradenark, manufacturer, or otherwise, does not necessarily constitute or inply its endorsement, recommendation, or favoring by the United states Government or any agency thereof or its contractors or subcontractors.

Printed in the United States of America. To obtain copies of this document, contect: WHC/BCS Document Control Services, P.0. Box 1970, Mailstop H6-08, Richland WA 99352, Phone (509) 372-2420; Fax (509) 376-4989.
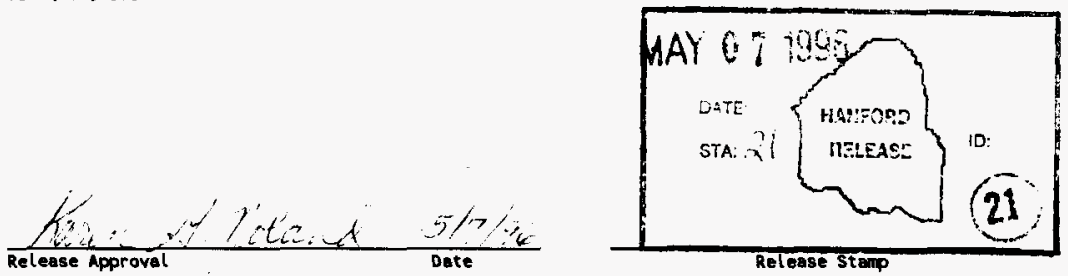

Approved for Public Release 
WHC-SD-TD-TRP-006, Rev 0

\section{CONTENTS}

POST DELIVERY TEST REPORT FOR THE LIGHT DUTY UTILITY ARM

HIGH RESOLUTION STEREOSCOPIC VIDEO CAMERA SYSTEM (HRSVS)

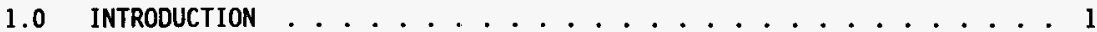

2.0 DESCRIPTION OF TEST . . . . . . . . . . ..... 1

3.0 TEST RESULTS .................... 2

4.0 CONCLUSIONS AND RECOMMENDATIONS .............. 4

5.0 DISPOSITION OF TEST ITEMS ................. 4

6.0 REFERENCES .................... 4 ATTACHMENTS

1. Completed Post Delivery Test Procedure for the Light Duty Utility Arm High Resolution Stereoscopic

Video Camera System (HRSVS) . . . . . . . . Att-1-1

2. Nondestructive Examination (NDE) Leak Test Report . . . A Att-2-1

3. Labview Virtual Instruments Used During the Post

Delivery Procedure ............. Att-3-1 


\section{POST DELIVERY TEST REPORT FOR THE LIGHT DUTY UTILITY ARM \\ HIGH RESOLUTION STEREOSCOPIC VIDEO CAMERA SYSTEM (HRSVS)}

\subsection{INTRODUCTION}

This report documents the post delivery testing of the High Resolution Stereoscopic Video Camera System (HRSVS), LDUA system number 6230, designed for use by the Light Duty Utility Arm (LDUA) project. The post delivery test was performed by the Remote System and Sensor Applications (RSSA) group and the Nondestructive Examination (NDE) group. The post delivery test shows by demonstration that the HRSVS is fully operational to perform the task of surveillance and inspection activities within a Hanford Site waste tank. The test did not include radiation testing or all environmental testing. These factors were reviewed during the design phases of the project and were deemed acceptable based on published data on radiation and environmental components used in the camera designs. Testing of the purge system to meet the requirements of NFPA 70 National Electrical Code (1993), Class 1 Division 1 , Group B requirements, NFPA 496, Standard for Purged and Pressurized Enclosures for Electrical Equipment (1993), and Hanford Safety Class 1 requirements for shutdown of the system was not performed. Full testing to meet these requirements will be performed during the overall LDUA qualification test. The HRSVS did undergo pressure and decon testing to demonstrate end effector integrity. An additional test to verify maximum external temperature of the HRSVS under normal operations was performed and documented. Completion of this post delivery test report signifies that the HRSVS is ready for integration testing with the LDUA Supervisory Data Acquisition System (SDAS).

\subsection{DESCRIPTION OF TEST}

The system under test is the LDUA system 6230, HRSVS. The property number is a Westinghouse Savannah River Company number, 00363307, with serial number 005 . The system tested included the HRSVS end effector, common video end effector electronics (CVEE), and the CVEE power supply. The HRSVS is the first stereoscopic end effector system developed for the LDUA program as part of the new technologies initiated through the U.S. Department of Energy's Office of Science and Technology. Figure 1 shows the HRSVS end effector, which includes internal cameras and lights.

Attachment 1 is the completed post delivery test describing each step of the test procedure. Attachment 2 is the completed NDE report. Attachment 3 is a computer print out of the Labview virtual instruments that were loaded to operate this system during testing. 
WHC-SD-TD-TRP-006, Rev 0

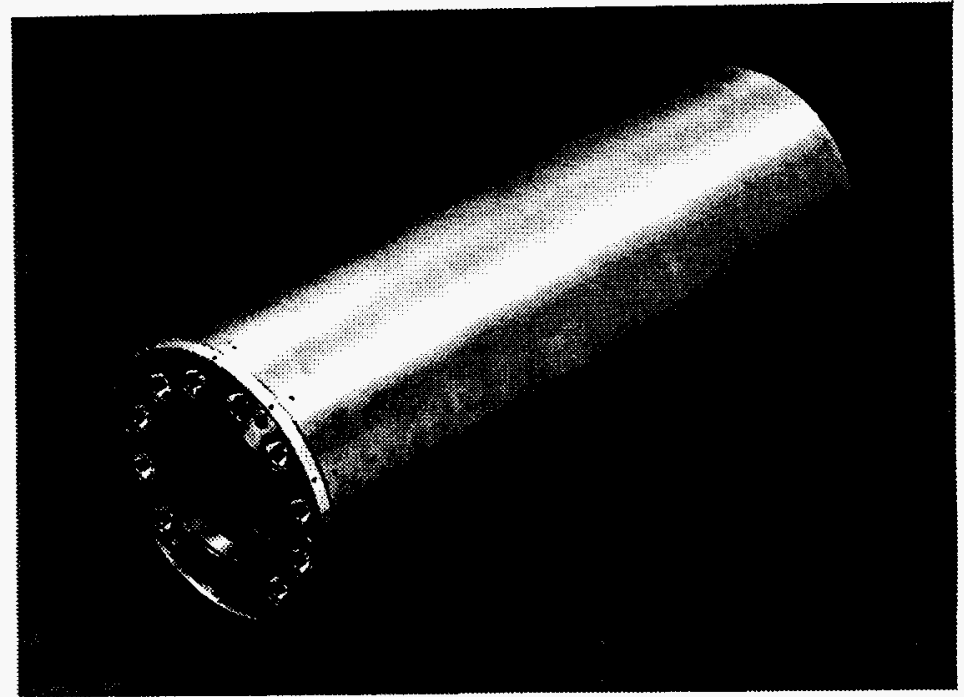

Figure 1. High Resolution Video Camera

system (HRSVS).

\subsection{TEST RESULTS}

The HRSVS system performed satisfactory during the post delivery testing. All system requirements were evaluated against the criteria in the test procedure. No exceptions occurred during the post delivery test.

It was noted in step 9 that no potentiometer exists on the large focusing lens. Without this potentiometer it is hard to discern where in the travel range the lens is. The time it takes for the lens to move from one end of its range to the other is 38.5 seconds at full speed. Therefore, an operator can set the lens approximately mid range by going one way for approximately 19 seconds at full speed. Further revisions to this end effector will consider using a method to mark the lens position.

The turret rotation potentiometer settings were noted as follows, (these are from steps 11, 12, and 13) and can be used during SDAS integration.

Voltage readings using the $50 \mathrm{~mm}$ lens.

PM3 (turret M3) -- 4.98 VDC

PM4 (turret M4) -- 4.95 VDC 
Voltage readings using the $25 \mathrm{~mm}$ lens.

PM3 (turret M3) $=-3.557$ VDC

PM4 (turret M4) -- 3.482 VDC

Voltage readings using the $16 \mathrm{~mm}$ lens.

PM3 (turret M3) -6.42 VDC

PM4 (turret M4) -- 6.44 VDC

The temperature test in step \#15 provided verification that the maximum external temperature of the protected enclosure was below the autoignition temperature of the flammable gas within the waste tank. The gas of concern in Hanford's waste tanks has been hydrogen which has an autoignition temperature of $520^{\circ} \mathrm{C}$. Figure 2 is a graphical display of the temperature rise of the HRSVS end effector until the temperature stabilized. The maximum temperature reached during the test was $172{ }^{\circ} \mathrm{C}$. This value is far below the autoignition temperature of hydrogen.

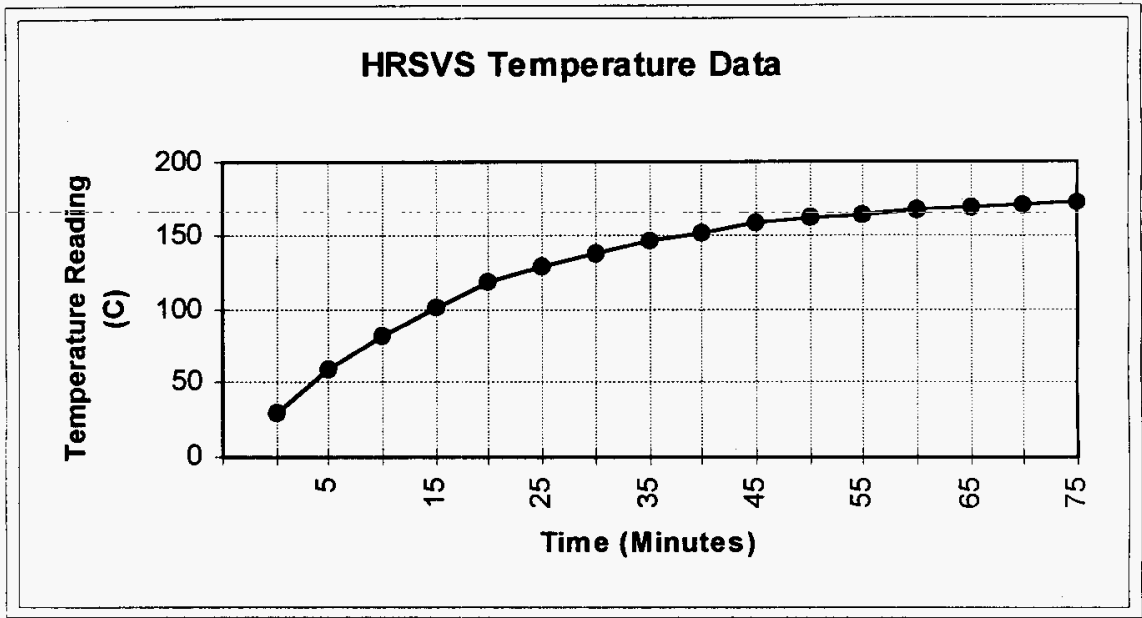

Figure 2 HRSVS Temperature Test

The decon test provided verification that the HRSVS end effector would not leak a substantial amount during the decon spray process. The HRSVS was brought to a downtown car wash and sprayed using a rinse nozzle which was operated at approximately 1000 psi. The spray wand was held at a distance of approximately 8 inches from the HRSVS and was moved from top to bottom (HRSVS was setting vertical on the ground) in approximately 3 seconds. This was done in 4 passes, 90 degrees apart, around the circumference of the end effector. The HRSVS was dried off externally and then dissassembled so the interior of the end effector could be examined. It was noted that there was no intrusion of water into the end effector. 
A pressure/leak test was performed to demonstrate integrity of the HRSVS under operating pressures of $+/-7$ inches of water. The system showed no visible degradation. A leak rate was measured to be approximately 9.2 standard cubic centimeters per second ( 9.2 STD CC / Sec) at the nominal LDUA operating pressure of 2.5 inches of water. This leak rate is considered to be acceptable. The leak was concentrated around the lower o-ring assembly near the front viewing end of the HRSVS.

\subsection{CONCLUSIONS AND RECOMNENDATIONS}

The post delivery test of the HRSVS demonstrated that the end effector system functioned according to design criteria established in the Westinghouse Hanford Company functions and requirements document WHC-SD-TD-FRD-003, Rev. 1, Functions and Requirements for the Light-Duty Utility Arm Integrated System (Kiebel 1996).

\subsection{DISPOSITION OF TEST ITEM}

The HRSVS end effector is now ready for integration testing with the LDUA SDAS system. It will remain in the Fuels and Materials Examination Facility until the completion of qualification testing.

\subsection{REFERENCES}

Kiebel, G. R., 1994, WHC-SD-TD-FRD-003, Functions and Requirements for the Light-Duty Utility Arm Integrated System, Westinghouse Hanford Company, Richland, Washington.

NFPA, 1993, National Electrical Code, National Fire Prevention Association, Batterymarch Park, Quincy, Massachusetts. 
WHC-SD-TD-TRP-006, Rev 0

\section{ATTACHMENT 1}

\section{COMPLETED POST DELIVERY TEST PROCEDURE \\ FOR THE \\ LIGHT DUTY UTILITY ARM \\ HIGH RESOLUTION STEREOSCOPIC VIDEO CAMERA SYSTEM (HRSVS)}

Att-1-1 
WHC-SD-TD-TRP-006, Rev. 0

POST DELIVERY TEST PROCEDURE

FOR

LIGHT DUTY UTILITY ARM

HIGH RESOLUTION STEREOSCOPIC VIDEO CAMERA SYSTEM (HRSVS)

MARCH 20, 1996

BY

A. F. PARDINI

REMOTE SYSTEM AND SENSOR APPLICATIONS

WESTINGHOUSE HANFORD COMPANY

RICHLAND, WASHINGTON 
This document provides for the post delivery testing of the High Resolution Stereoscopic Video Camera System (HRSVS) end effector used for surveillance and inspection activities during deployment operations with the Light Duty Utility Arm (LDUA) system.

\section{Approvals:}

End Effector Cognizant Engineer, Design Agentf Date 4/10/96

Technical Lead Engineer, Design Authority

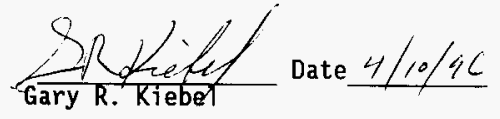

LDUA Test Director

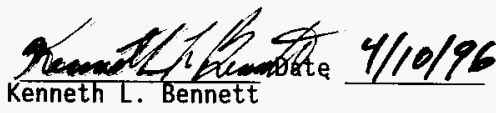

Safety

Travis M Amumelen Date $4 / 10 / 96$
Travis M. Amundson 
WHC-SD-TD-TRP-006, Rev. 0

TABLE OF CONTENTS

POST DELIVERY TEST REPORT

FOR

LIGHT DUTY UTILITY ARM

HIGH RESOLUTION STEREOSCOPIC VIDEO CAMERA SYSTEM (HRSVS)

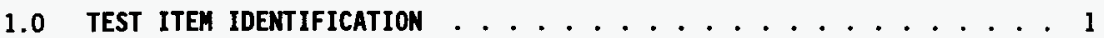

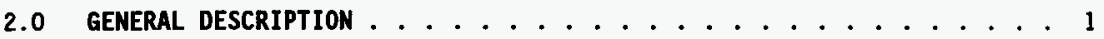

3.0 TEST CONDITION LIMITS ..................... 1

3.1 EXCEPTIONS . . . . . . . . . . . . . . . 2

4.0 INSTRUMENTS AND CALIBRATION ................. 2

5.0 FACILITIES, EquIPMENT, AND MATERIALS ............. 2

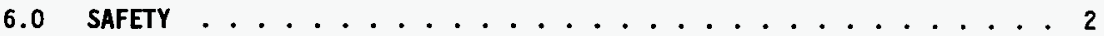

7.0 MAINTENANCE AND faIluRES ................. 3

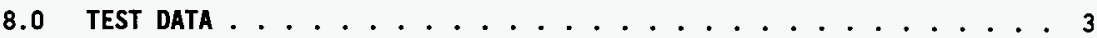

9.0 PERSONNEL REQUIREMENTS ................ 3

10.0 HITNESSES ..................... 3

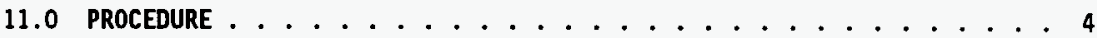

12.0 DISPOSITION OF TEST ITEM .................. 4

13.0 DATA SHEETS....................... 4

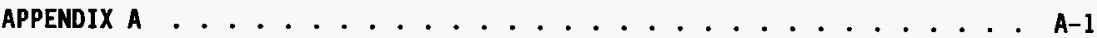

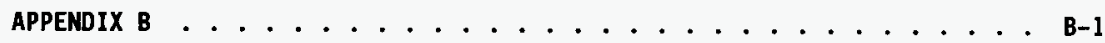


WHC-SD-TD-TRP-006, Rev. 0

\section{POST DELIVERY TEST PROCEDURE \\ LIGHT DUTY UTILITY ARM \\ HIGH RESOLUTION STEREOSCOPIC VIDEO CAMERA SYSTEM (HRSVS)}

\subsection{TEST ITEM IDENTIFICATION}

The system under test is the Light Duty Utility Arm (LDUA) system 6230, High Resolution Stereoscopic Video Camera System (HRSVS). The property number is a Westinghouse Savannah River Company number, 00363307 , and the serial number is 005 . The system to be tested includes the end effector and control electronics.

\subsection{GENERAL DESCRIPTION}

The objective of the test is to show by demonstration that the HRSVS is fully operational to perform the task of surveillance and inspection activities during deployment operations with in a Hanford waste tank. The test will not include radiation testing or all environmental testing. These factors were reviewed during the design phases of the project and were deemed acceptable based on published data on radiation and environmental components used in the camera designs. Testing of the purge system to meet the requirements of NFPA 70 National Electrical Code (1993), Class l Division 1, Group B requirements, NFPA 496, Standard for Purged and Pressurized Enclosures for Electrical Equipment (1993), and Hanford Safety Class 1 requirements for shutdown of the system will not be performed during this test. Full testing to meet these requirements will be performed during the overall LDUA qualification test. Testing will include a pressure test to verify end effector integrity under the normal operating pressures, a decon spray test to assure that water does not leak into the end effector, and an additional test to verify maximum temperature of the camera under normal operations. Upon completion of this post delivery test, the HRSVS will be ready for integration testing with the LDUA Supervisory Data Acquisition System (SDAS).

\subsection{TEST CONDITION LIMITS}

Test conditions which could cause the test to be aborted would be a loss of power in the facility, or complete failure of the camera system to perform its intended functions. If either of these occur, the test will be suspended until the problems are resolved. After probiem resolution, the test will be resumed. If necessary, sections of the test may be repeated at the discretion of the end effector cognizant test engineer. 


\subsection{EXCEPTIONS}

Exceptions noted during the execution of the test procedure shal1 be recorded in the spaces provided in Appendix $A$. If an exception is noted, applicable signatures must obtained prior to continuing the test procedure. If no exceptions occur, write "none" and cont inue the procedure.

\subsection{INSTRUMENTS AND CALIBRATION}

A temperature indicating device will be used to measure the temperature of the outside of the camera from initial startup until a stabilized maximum temperature is reached. This device will have a current calibration sticker from the Standards Laboratory. During pressure testing, a pressure gauge will be used to measure pressures inside of the end effector. This sensor shall have a current calibration sticker from the Standards Laboratory.

\subsection{FACILITIES, EQUIPMENT, AND MATERIALS}

The HRSVS will be tested in the Fuels and Materials Examination Facility (FMEF) on the 42' $-6^{\prime} '$ ' level and in the Nondestructive Examination Laboratory in 306E. The equipment and materials listed below are necessary to perform this post delivery test:

- HRSVS camera system, including Common Video End Effector Electronics (CVEE), CVEE power supply, and LDUA test umbilical

- Computer (486 or better PC running Windows $3.11^{\star}$ with program software Labview 3.1.1\%^

- Stereographics monitor, view record system, and stereo glasses

- I1OVAC power source and power strip

- Calibrated temperature indicating device and thermocouple

- Calibrated pressure gauge

- Leak test equipment (to be provided by NDE group)

- Water, water hose, and spray nozzle

- Miscellaneous (e.g. duct tape, common tools, etc.)

\footnotetext{
* Windows is a trademark of Microsoft Corporation.

**Kabview is a trademark of National 2

Instruments Corporation, Austin, TX.
} 


\subsection{SAFETY}

The HRSVS system will be tested with its outer shell removed so that the internal mechanical assembly can be observed. The HRSVS electrical connections are low voltage $(<35 \mathrm{~V})$. Test personnel shall keep hands away from the electrical and mechanical assemblies during this testing. Exposed wiring at the Hypertronic connections is also low voltage.

During temperature testing, the surface of the end effector may reach approximately 140 degrees Celsius, therefore care must be taken by test personnel during this testing. A sign reading "HOT, DO NOT TOUCH", will be located next to the end effector.

\subsection{MAINTENANCE AND FAILURES}

There are no components within the HRSVS which should require maintenance during the testing period. If any component fails during the testing period, and it can be replaced immediately, then the condition shall be documented under the exception portion of Appendix $A$ and testing shall continue. If the failure is catastrophic (component cannot be readily replaced or needs to be reordered) then the procedure will be stopped and repeated at a later date.

The extent of the HRSVS post delivery test should be short in duration, so no test interruptions are expected.

\subsection{TEST DATA}

Test data from the temperature and pressure measurements will be logged into the appropriate sections of Appendix A. A graphical plot depicting temperature versus time will be documented in an Post Delivery Test Report. During the post delivery test the witnesses will sign off in appropriate sections of the test procedure to indicate that the equipment is operating as expected.

\subsection{PERSONNEL REQUIREMENTS}

All personnel involved in the performance of this test shall print and sign their name, initials, position, and date of signature prior to beginning the testing in the personnel record section of Appendix $A$.

The operation of the equipment will be performed by the LDUA end effector cognizant engineer and/or designated end effector technician. This person will perform the operations and the LDUA end effector 
cognizant engineer will sign off the associated steps as to their acceptance. Temperature and pressure data may be transcribed by the end effector technician.

\subsection{WITNESSES}

All witnesses will be notified immediately proceeding the beginning of the test. They shall witness the procedure and concur the successful completion of specific steps with either their signature or their initials and date. If exceptions are noted and are acceptable then the LDUA cognizant engineer shall record the exception, write in the resolution, and sign and date. All other specific witnesses addressed in the exception shall also sign and date. If the exception is such that no immediate resolution is attainable, the test will be aborted until the problems are resolved. Once resolved the test will be repeated at a later date. hours.

It is expected that the complete test will last no more than 8

\subsection{PROCEDURE}

Appendix A provides the step-by-step procedure for testing the HRSVS. Appendix $A$ also includes the personnel record, pressure data, and the temperature data sheet. Appendix B provides pictures of the components used as part of this post delivery test. It provides a visual reference to those components described in the test procedure.

\subsection{DISPOSITION OF TEST ITEM}

All test materials will remain in the FMEF test facility for future use. The actual end effector system tested will now be ready for integration testing with the LDUA SDAS system.

\subsection{DATA SHEETS}

No further data sheets will be necessary to support the testing of this end effector system. All verifications of testing will be signed directly within this procedure under Appendix $A$. 
WHC-SD-TD-TRP-006, Rev. 0

\section{APPENDIX A \\ LIGHT DUTY UTILITY ARM \\ HIGH RESOLUTION STEREOSCOPIC VIDEO CAMERA SYSTEM (HRSVS) \\ POST DELIVERY TEST PROCEDURE}

This procedure will be used to perform the actual post delivery testing of the HRSVS system. As each step is performed signatures shall be logged onto the procedure in the blank spaces as indicated. Major tests may be performed out of sequence (i.e. Functionality testing may be performed before the decontamination test).

Step 1: Notify all witnesses (to include End Effector Cognizant Engineer, NDE personnel, and End Effector Technician) immediately prior to commencing the test.

\section{DECONTAMINATION TEST}

Step 2: Transport the HRSVS to a facility which has a high pressure water wash system ( $500 \mathrm{psi})$. Seal the end of the HRSVS with a gasket seal and cover plate. Set the HRSVS upright on a piece of foam at ground level. Use a metal pole secured to the top of the HRSVS to stabilize during the wash down.

WARNING, WATER SPRAY AT 500 PSI CAN BE HAZARDOUS. USE CARE TO ASSURE THAT PERSONNEL ARE PROTECTED FROM THE SPRAY.

Using the high pressure water spray, rinse the exterior of the HRSVS uniformly. Move the spray wand from top to bottom, covering the length of the HRSVS in roughly 3 seconds. Perform this spray test at 0 degrees, 90 degrees, 180 degrees, and finally at 270 degrees around the circumference of the HRSVS. Discontinue the water rinse and immediately dry off the exterior of the HRSVS. Remove the gasket seal and cover plate so that the interior of the HRSVS can be examined for any water intrusion. Reassemble after assessment has been made.

Duration of water spray: $\simeq 12$ Total Seconds

Fan angle of water spray: 60 deques 


$$
\text { WHC-SD-TD-TRP-006, Rev. } 0
$$

Distance from nozzle to HRSVS: $\sim 8$ inches

Estimate of water pressure: 1000 psi at nozzle

Estimate of water intrusion

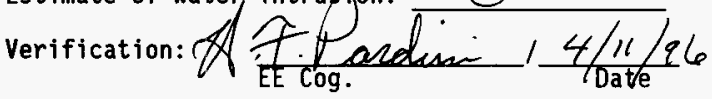

Exceptions/Notes:

The HRSUS experienced no water intrusion.

This completes the deco test.

PRESSURE/LEAK TEST

Step 3: Transport the HRSVS end effector, cover plate assembly, and calibrated pressure gauge to the $306 \mathrm{E}$ facility. The NDE group will perform an information only pressure/leak test. This test will provide a visual assessment of the integrity of the HRSVS when subjected to a $+/-7$ inches of water pressure, and a quant itative assessment of the leak rate out of the HRSVS under the assumed maximum purge pressure of 7 inches of water. The post delivery test report will include the NDE test data.

Verification:

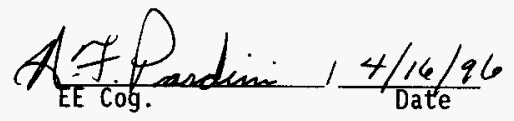

Exceptions/Notes:

None.

This completes pressure testing.

A-2

Att -1-10 


\section{FUNCTIONALITY TEST}

Step 4: Transport the HRSVS to the mezzanine level of FMEF. Remove the outer cover shell of the HRSVS exposing the interior mechanical assembly. Position the HRSVS on the nylon test fixtures used for HRSVS testing. Level the HRSVS so that the cameras are level in the $X$ and $Y$ directions. Connect the LDUA umbilical between the CVEE box and the connectors on the HRSVS. The Hypertronic connectors have been pre-marked. Only the end effector cognizant engineer or his designee can perform this step. Connect a11 other wiring as show in the Figure 1 . This test configuration will test the end effector, the wiring interface between the end effector and the CVEE which will be located in the At Tank Instrument Enclosure (ATIE), and the operation of the CVEE. Since the LDUA is not yet at Hanford, this test configuration will simulate the final conditions. Complete integration testing will be performed as the components are completed and assembled. Full testing will be performed during LDUA qualification testing.

Verification:

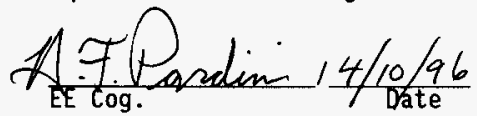

Exceptions/Notes:
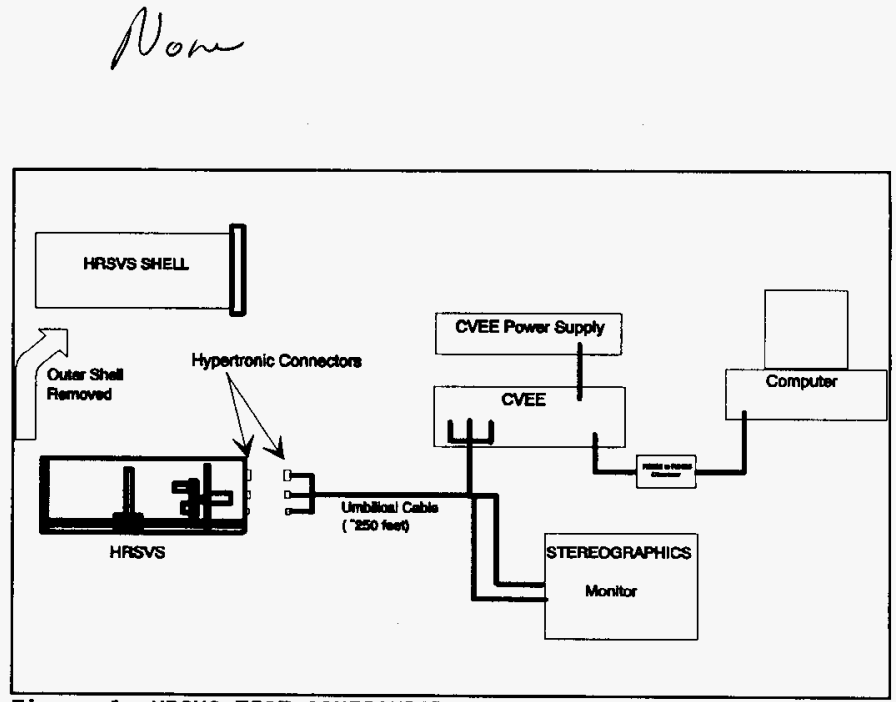

Figure 1 HRSVS TEST CONFIGURATION 
Step 5: Plug in the power cord supplying power to the CVEE, computer, monitor, Stereographics System, TV monitor, and CVEE power supply chassis. Power up the system. This power up will include turning on each supply on the front of the CVEE power supply chassis using the toggle switches. LED's above each of the toggle switches should light up.

Verification:

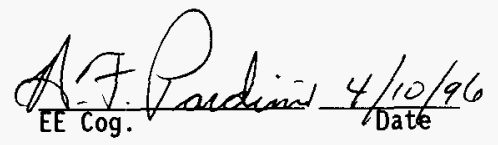

Exceptions/Notes:<smiles>[14CH3]</smiles>

Step 6: Record the make and model of the computer system.

Computer: $A 57 T^{*} 46 / 33$ Model \# Hemmia $4 / 33$

Turn on computer power. Also record version of software used. Windows Software: Version 3.11 Windows toubdrgroups Labview Software: Version 3.1.1

Record the 1 ist of virtual instruments and their revision level that are booted on the system and include in the post delivery test report.

Computer system shall now be in "boot" procedure. Wait until it has booted into the "Labview" window. The HRSVS has a black and white video camera inside. The separate television monitor should provide a visual feed from the HRSVS camera. If no picture is

ॠAST is a trademark of AST Research, Inc.

$$
\text { A-4 }
$$


present, make sure all coaxial connections have been made. If the camera system has failed, suspend the test.

Verification:

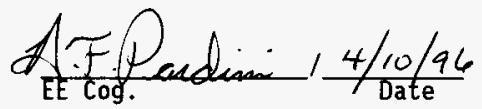

\section{Exceptions/Notes:}<smiles>CC1CC1</smiles>

Step 7: Double click on the "Labview" icon. The "untitled 1" window will come up. Open the file called "CVEES", then open "Unit.LLB", and then open "CVEES Main.VI". The "CVEES Screen Selection" should be on the monitor. Using the run command ("arrow") directly below the word file, run the VI. When this instruction is pressed, the "Init Mode Control Screen" will be on the monitor. Press the blue "Screen Select" button. The next screen should be the "CVEES Screen Selection" as before. Now press the HRSVS End Effector button. The HRSVS main function control screen (virtual instrument) should now be operational. To test this, touch the Gl button with the mouse and click. A pair of lights on the HRSVS should turn on. If not, make sure all power connections are on and perform the boot procedure again. If there still is no function control suspend the test.

Verification:

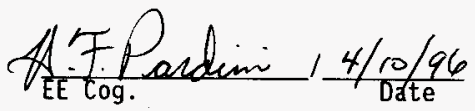

Exceptions/Notes:

Nore 
Step 8: Position the HRSVS so that the LDUA test target can be viewed approximately 2 feet in front of the camera. The HRSVS should be set so that the large focusing lens is midway in its travel and the $50 \mathrm{~mm}$ pair of lens are in front of the two Sony cameras. Position the test target so that it is in focus and centered along the axis of the HRSVS as seen on the Stereographics monitor. Each set of lights will now be tested. Using the mouse button click on the G1 button. The first pair of lights should come on. Verify that they are on and are bright. Turn off G1. Now turn on G2. Again verify that they are on and are bright. Turn off G2.

Repeat these steps for G3, G4, and G5. After each 1ight pair has been shown to operate properly, turn on all light pairs and verify they are all on and are bright. Turn off all the lights except GI.

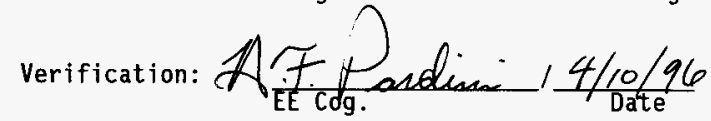

Exceptions/Notes:

Test target placed at 29 inches.

Step 9: In this step we will test the HRSVS control functions. The slider to the right of each control button is a speed controller. To begin with position the speed controller to the mid point for each function. During this step and those following the speed adjustment can be used to slow down those functions, such as turret rotation, that are difficult to perform for precise image alignment. The speed adjustment can also be used to speed up the operation when there is a desire to move rapidly to a new setting. Using the Closeup "FAR" function, move the large focusing lens until it stops just in front of the turret assemblies. A microswitch is located along the bottom rail of the frame assembly and shuts off the lens movement when the large focusing lens get close to the turret. Using the Closeup "NEAR" function, move the large focusing lens the other direction until it contacts the microswitch near the end of the end effector and shuts off.

$$
\text { A-6 by the liqhts of } \mathrm{fP}_{4 / 10} \mathrm{9}^{6}
$$


Verify that the focusing lens movement is unincumbered in the complete focus range and the focusing lens stops at these microswitch shutdown locations. Verify that the speed control function is operating by moving the large lens at the near 0.0 setting and at the 1.0 setting (note: the motor will not operate with 0.0 volts applied so the setting for slow speed is slightly above the 0.0 setting). Return the large focusing lens to the midway point of its travel.

Verification:

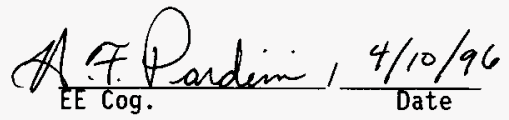

Exceptions/Notes:

$$
\text { Nore }
$$

Note: No potentionter exists on the lange focusingn lens. The total time it takes te lens to move from one end fo ta other is 38.5 secs at full speed. During openation thopunator can set this lens approximately half way in its travel by going one way from its stopped position for approximately 19 seconds.

Step 10: To test the camera convergence use the Convergence "NEAR" and "FAR" functions and observe the Stereographics monitor. The two images on the screen should move apart and then back together. Since the convergence mechanical assembly is simply a rotating cam, either "NEAR" or "FAR" buttons can be used to demonstrate proper function. Verify that the images move apart and then back together smoothly with little or no hesitation. Verify that the speed control for this function is operational.

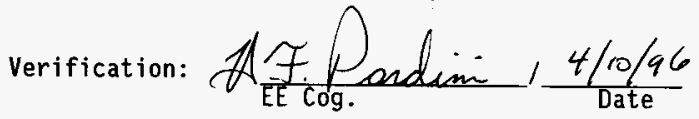

Exceptions/Notes:<smiles>[Li][13CH3]</smiles> 
Step 11: In step 8 the two $50 \mathrm{~mm}$ lens were positioned in front of the two stereo cameras. Using the $M 3$ " $\mathrm{CCW}$ " and "CW" functions rotate turret $M 3$ until the $50 \mathrm{~mm}$ lens is precisely aligned on the LDUA target. The image can be viewed on the Stereographics monitor during the rotation. Set the image of the LDUA test target in the middle of the monitor. Using the M4 "CCW" and "CW" functions on turret $\mathrm{M4}$, rotate the turret until this $50 \mathrm{~mm}$ lens is in front of the camera. The image can be viewed on the Stereographics monitor during the rotation. Using these rotation functions, align the two images so they are aligned in the vertical plane. Verify that the speed control is operational during this al ignment procedure. Using the convergence function, adjust so that the images are very near to overlaying each other, allowing for a small space between the two images (1/4 inch apart as viewed on the screen). Using the stereo glasses verify that the image is clear and in 3D.

(Note: Viewer must be capable of seeing in 3D)

Verification:

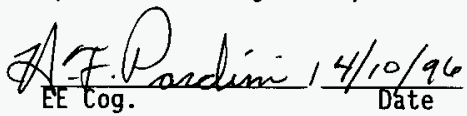

Exceptions/Notes: $\$ 1$ \&10 196

PM 3 Potentioneter readingfol. $4.98 \mathrm{VDC}$

$\mathrm{Pm} 4$ Potentionter reading is $4.95 \mathrm{VDC}$

Step 12: Using the M3 "CW" function for turret M3 rotate the turret clockwise until the $25 \mathrm{~mm}$ lens is in front of the camera. The image can be viewed on the Stereographics monitor during the rotation. Set the image of the LDUA test target in the middle of the monitor. Using the M4 "CCW" function for turret M4, rotate the turret counterclockwise until the $25 \mathrm{~mm}$ lens is in front of the camera. The image can be viewed on the Stereographics monitor during the rotation. Using these rotation functions, align the two images so they are preciseiy aligned in the vertical plane. 
WHC-SD-TD-TRP-006, Rev. 0

Using the convergence function adjust so that the images are very near to overlaying each other, allowing for a small space between the two images. Using the stereo glasses verify that the image is clear and in 3D. (Note: Viewer must be capable of seeing in 3D)

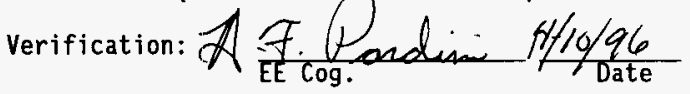

Exceptions/Notes:

PM 3 Pot reading is $3.557 \mathrm{VDC}$

P 4 Pot reading is $3.482 V D C$

Step 13: Using the M3 "CCW" function for turret M3 rotate the turret counterclockwise until the $16 \mathrm{~mm}$ lens is in front of the camera. The image can be viewed on the Stereographic monitor during the rotation. Set the image of the LDUA test target in the middle of the monitor. Using the M4 "CW" function for turret M4, rotate the turret clockwise until the $16 \mathrm{~mm}$ lens is in front of the camera. The image can be viewed on the Stereographic monitor during the rotation. Using these rotation functions, align the two images so they are precisely aligned in the vertical plane. Using the convergence function adjust so that the images are very near to overlaying each other, allowing for a small space between the two images. Using the stereo glasses verify that the image is clear and in 3D. (Note: Viewer must be capable of seeing in 3D)

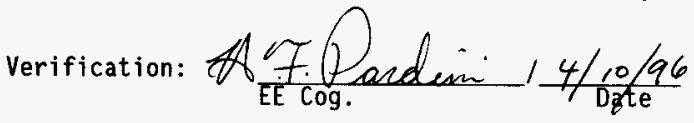

Exceptions/Notes:

Pm 3 Pot reading is Ce. 42 VAC Pm 4 Pet reading is $6.44 \mathrm{VDC}$

A-9

Att -1-17 
WHC-SD-TD-TRP-006, Rev. 0

Step 14: Using the "Camera Select" function change the cameras from the Sony cameras to the Watec black and white cameras. Verify that each Watec camera is operational and in focus and with proper iris setting by simply covering one of the Watec cameras and viewing on the Stereographic monitor. Then remove the cover on the first camera and cover the second camera and view the image on the monitor.

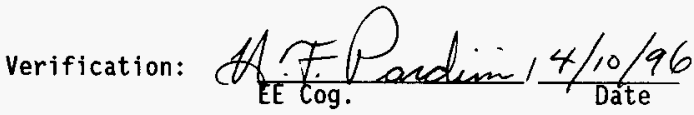

Exceptions/Notes:

Nome

This completes the HRSVS functionality test. Place the outer cover shell back over the HRSVS mechanical assembly.

A-10

Att -1-18 


\section{CAMERA TEMPERATURE TEST}

Step 15: Place the HRSVS in a position so that the heat from the lights will not cause any hazard. Connect the temperature indicating device to the front face of the HRSVS using a thermocouple under the cap screw next to the lighting.

Instrument name and manufacturer:ivital Thermometer, Omega

Mode1 Number: $H H-99 \mathrm{~J}$

Standards Lab Number: $770-79-06-008$

Expiration Date: $11-1-96$

On the temperature data sheet, record the initial temperature (no camera lights). Turn on all lights using buttons Gl through G4. Leave the camera lights on and begin taking temperature data and documenting on the temperature data sheet.

\section{WARNING: CAMERA LIGHTS WILL GET HOT. ASSURE PERSONNEL ARE PROTECTED AGAINST THE HAZARDS.}

Data will be taken every 5 minutes until the temperature stabilizes (temperature has stabilized when the temperature change over a 5 minute interval is 2 degrees or less for three consecutive readings). After completion, shut off the lights and remove the thermocouple.

Verification:

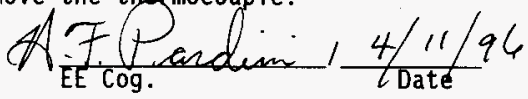

Exceptions/Notes:<smiles>CCCC1=CC=CC1C</smiles>

This completes the temperature test.

This completes the post delivery test of the HRSVS. To shutdown the system, choose the blue "Screen Select" button on the HRSVS VI. Then choose the blue "System Stop" button. You may now close all windows in the normal manner and power down the system. 


\section{FINAL POST DELIVERY TEST APPROVAL RECORD}

This post delivery test has been completed and all exceptions resolved to the satisfaction of all applicable witnesses and that the High Resolution

Stereoscopic Video Camera System is now available for integration with the Light Duty Utility Arm Supervisory Data Acquisition System.

LDUA End Effector Cognizant Engineer Hon 7 . Tardem Date $4 / 16 / 96$ 


\section{TEMPERATURE DATA SHEET}

The temperature of the HRSVS system is taken to verify that the external temperature of the protected enclosure is sufficiently below the autoignition temperature of the flammable gas within the waste tank. The temperature reading is taken with the thermocouple located adjacent to the lights on the camera module which is expected to be the hottest area.

\begin{tabular}{|c|c|}
\hline TIME (Minutes) & $\begin{array}{c}\text { TEMPERATURE } \\
\text { REEDING } \\
\text { (degrees C) }\end{array}$ \\
\hline 0 & 30 \\
\hline 5 & 59 \\
\hline 10 & 82 \\
\hline 15 & 101 \\
\hline 20 & 118 \\
\hline 25 & 129 \\
\hline 30 & 138 \\
\hline 35 & 146 \\
\hline 40 & 152 \\
\hline 45 & 158 \\
\hline 50 & 161 \\
\hline 55 & 164 \\
\hline 60 & 167 \\
\hline 65 & 169 \\
\hline 70 & 170 \\
\hline 75 & 172 \\
\hline & \\
\hline
\end{tabular}


WHC-SD-TD-TRP-006, Rev. 0

PERSONNEL RECORDS

\begin{tabular}{|c|c|c|c|c|}
\hline $\begin{array}{l}\text { NAME } \\
\text { PRINT }\end{array}$ & $\begin{array}{l}\text { SAME } \\
\text { SLGN }\end{array}$ & INITIALS & POSITION & DATE \\
\hline Allan EPardin: & Art $Y$ andini & Af $P$. & EE Cog Eng. & $4 / 10 / 96$ \\
\hline Cheistopker M.Smin & Contunests & Cunt & $M E \operatorname{Cog} \cdot \varepsilon_{x}$ & $4 / 10 / 96$ \\
\hline W. D. Purdu & W.DPadu & $\omega D+D$ & NDE Techous & $4 / 5 / 96$ \\
\hline & & & & \\
\hline & & & & \\
\hline & & & & \\
\hline & & & & \\
\hline & & & & \\
\hline & & & & \\
\hline
\end{tabular}




\section{WHC-SD-TD-TRP-006, Rev. 0 APPENDIX B}

\section{LIGHT DUTY UTILITY ARN \\ HIGH RESOLUTION STEREOSCOPIC VIDEO CAMERA SYSTEM COMPONENTS}

Figures 2, 3, 4, 5, and 6 show the components used in the post delivery testing of the HRSVS.

B-1

Att-1-23 
WHC-SD-TD-TRP-006, Rev. 0

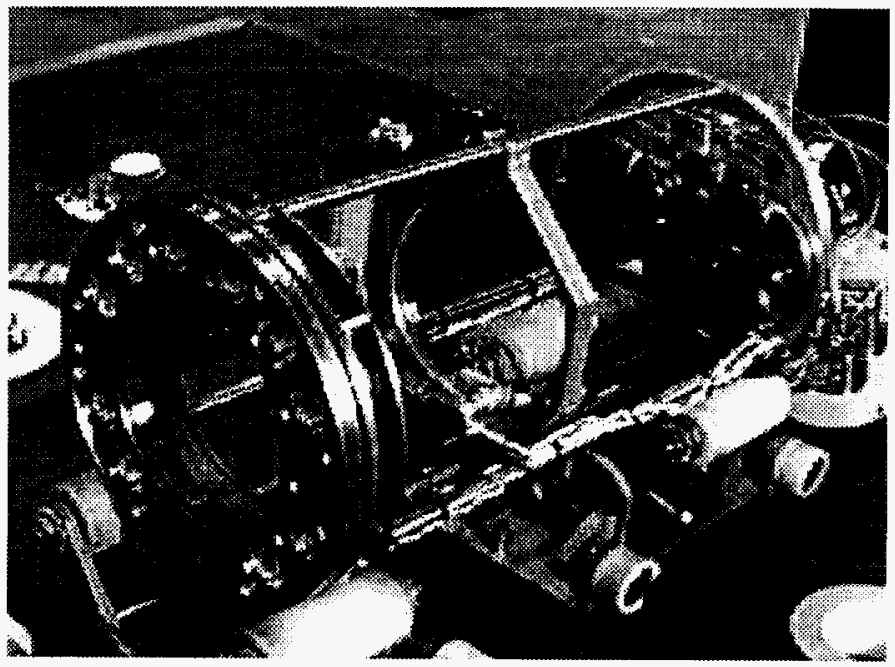

Figure 2 High Resolution Stereoscopic Video Camera System on Test Fixture

B-2 


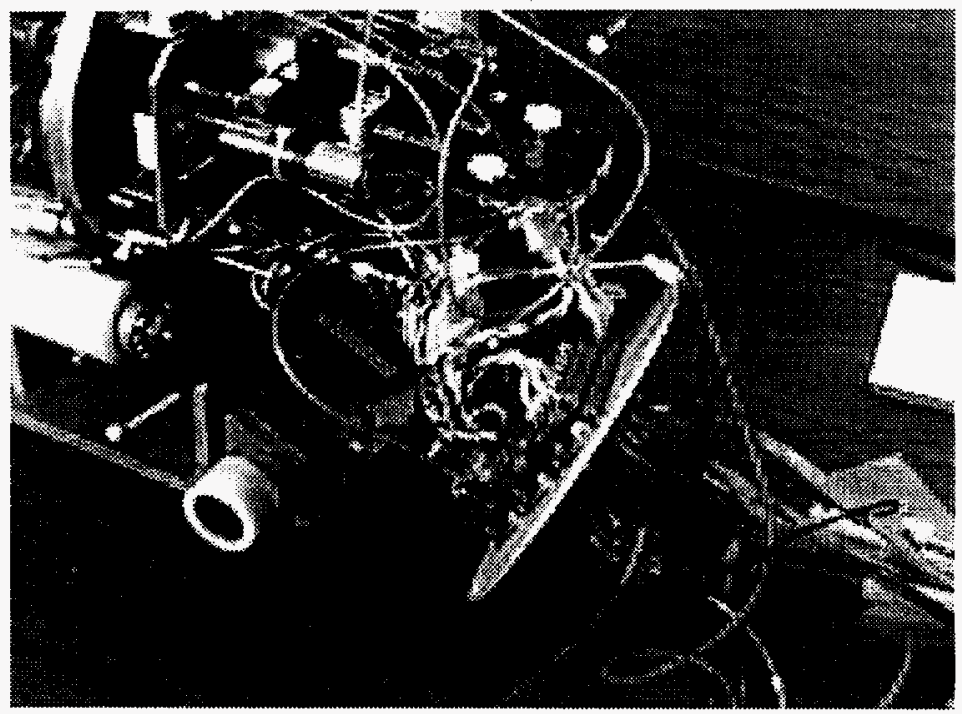

Figure 3 Hypertronic Connection

B-3

Att-1-25 
WHC-SD-TD-TRP-006, Rev. 0

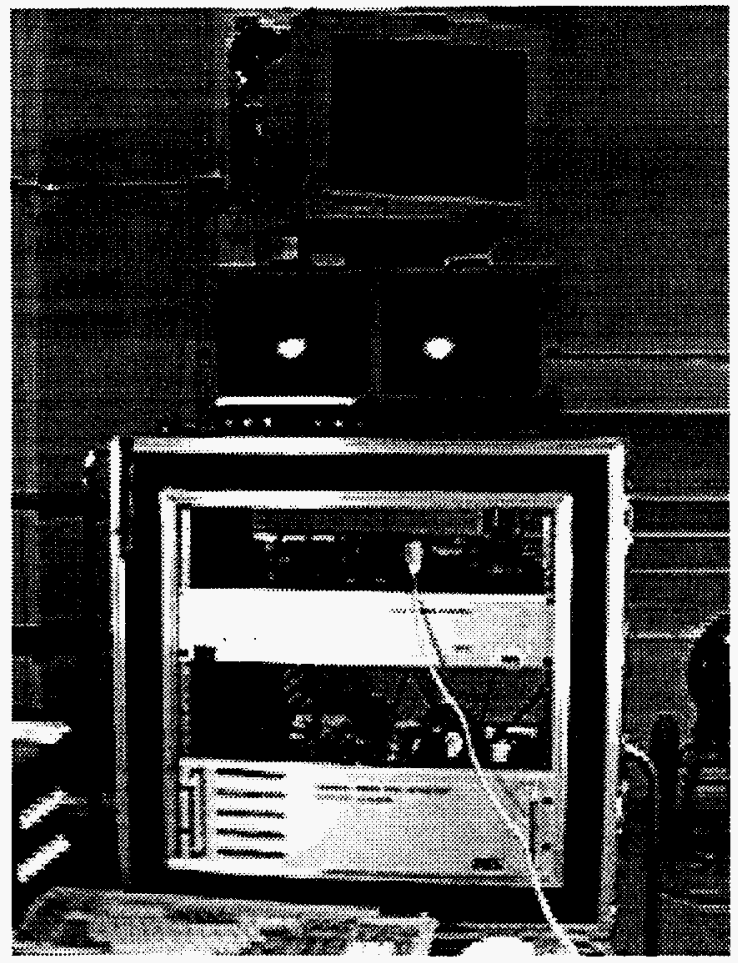

Figure 4 Computer Interface 
WHC-SD-TD-TRP-006, Rev. 0

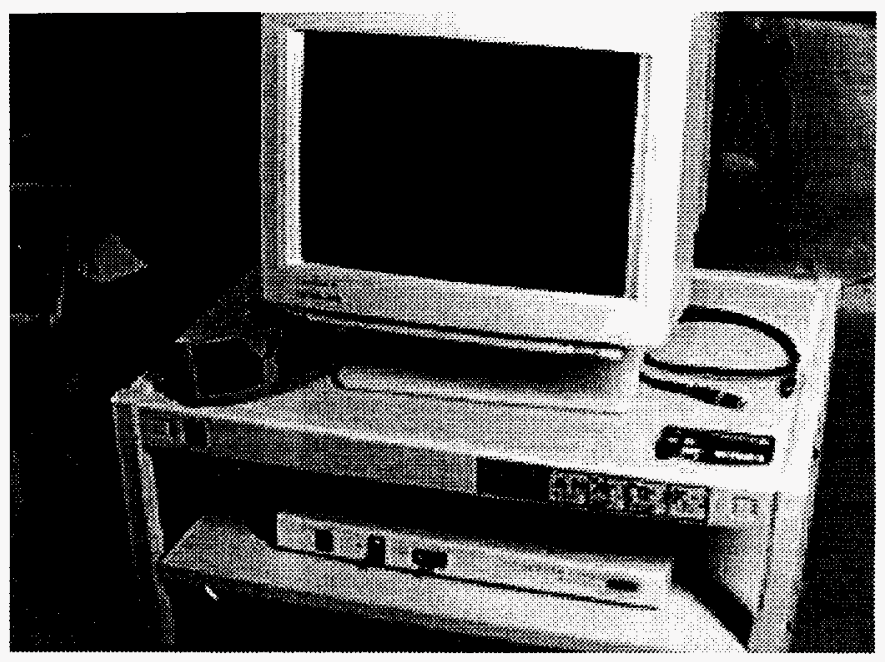

Figure 5 Stereographic Monitor and View Record System

B-5 
WHC-SD-TD-TRP-006, Rev. 0

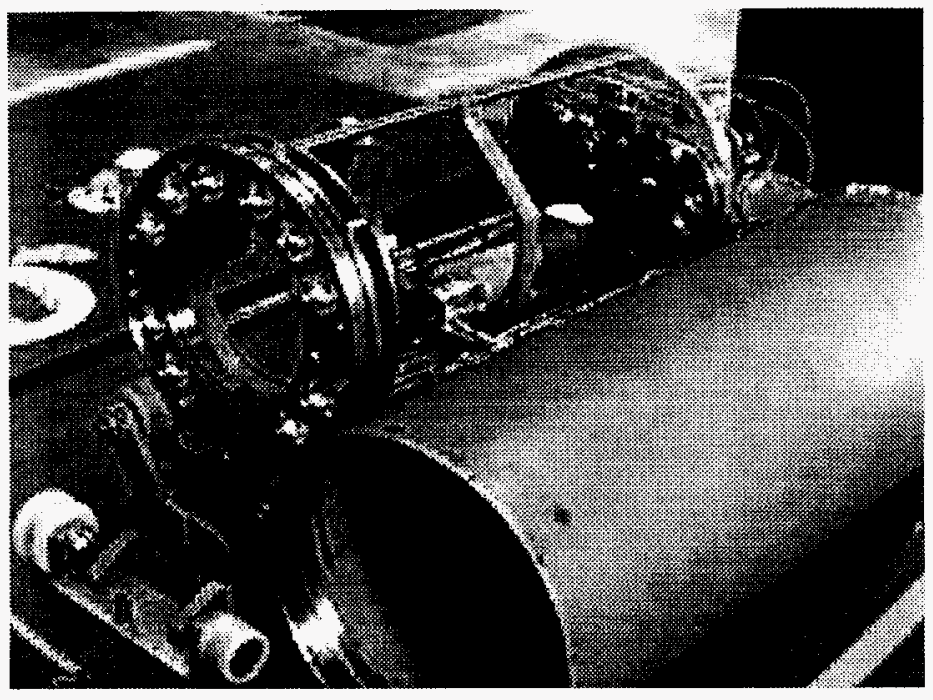

Figure 6 HRSVS with the Outer Shell Removed. 
WHC-SD-TD-TRP-006, Rev 0

ATTACHMENT 2

NONDESTRUCTIVE EXAMINATION

LEAK TEST REPORT

OF

HIGH RESOLUTION STEREOSCOPIC VIDEO CAMERA SYSTEM (HRSVS)

Att-2-1 
WHC-SD-TD-TRP-006, Rev. 0

\section{NDE LEAK TEST PROCEDURE AND TEST REPORT UL-100}

NON DESTRUCTIVE EXAMINATION

306 BLDG., 300 AREA . TEL. 376.5401

$96-25$

Requestor

A. PARDINI

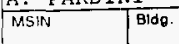

N1 $1-23$

Accepiance Std.

FOR INFORMATION ONLY

Company Project/System/Work Package/Traveler No.

LIGHT DUTY UTILITY ARM END EFFECTOR. THE HIGH RESOLUTION

WHC

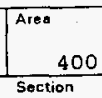

STEREOSCOPE VIDEO SYSTEM (HRSVS) H1BO1

Date
X NA

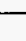

$\square$ NA Dwg. No.

\section{TEST CONDITIONS}

Temperature AMB. Device ID

Barometric Pressure AMB.

Iest Pressure 7 INCHES OF WATER $\square$ NA

Gas NITROGEN

Concentration APPROX. 100 \&

Other

Bubble Solution

Batch No.

$534-2 \overline{8}-09-005$

Gsge 1 . 5ot

Range $0-10$ IN. OF $\mathrm{H} 2 \mathrm{O}$

Calib. Exp. 3-12-99

wpP 4 lialak $679-28-03-024$

Pange $0-10 \mathrm{~K}$ SCCM N2

Calib. Exp. 9-8-96

Retief Valve

Recied

Weld No., Part No., or Serial No. HRSVS

\begin{tabular}{|l|l}
\hline HRSVS & . \\
\hline & \\
\hline & \\
\hline & \\
\hline & \\
\hline & \\
\hline & \\
\hline & \\
\hline
\end{tabular}

Technique Pre Approval

$\mathrm{X}$. NA

Technicisn

WD PURDY

WD Sus reste

$04 / 16 / 96$

目 ${ }^{N A}$

国 ${ }^{N A}$

$\square$ NA $X]^{N A}$
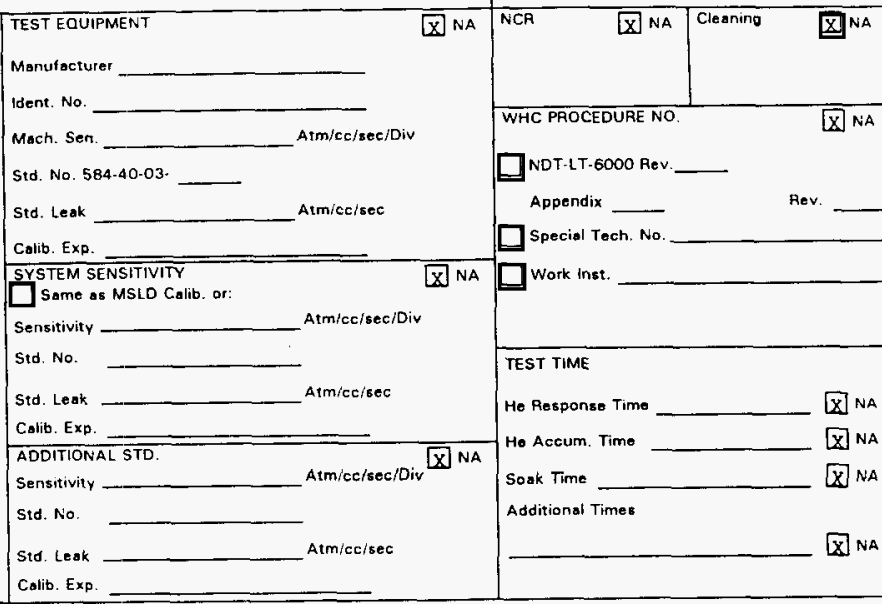

WHC PROCEDURE NO

X. NA

$\square$ NDT-LT-6000 ReV

Appendix

$\square$ Special Tech. No.

\begin{tabular}{|l|l|l|l|}
\hline Acc. & Rej. & $\begin{array}{c}\text { No Rel } \\
\text { Ind }\end{array}$ \\
\hline & & & \\
\hline & & & \\
& & & \\
& & &
\end{tabular}

POSITIVE AND NEGATIVE PROOF TEST AT 7 INCHES OF WATER

APPEARED TO CAUSE NO PHYSICAL DAMAGE - PERFORMED LEAK

RATE TEST USING A MASS FLOW METER . THE AVERAGED LEAKAGE

FLOW RATE AT $1.0,2.0,2.5,3.0,4.0,5.0,6.0 \approx 7.0$

INCHES OF WATER ARE RESPECTIVELY 4.00, 7.20,9.20,9.70,

$12.16,15.66,17.33,20.33, \mathrm{SCC} / \mathrm{S}$ (SEE ATTACHED

DATA SHEET).
TEST TIME

He Response Time [x] NA [X] NA [X] NA [X] NA

\begin{tabular}{l|l}
$12.16,15.66,17.33,20.33$, SCC/S (SEE ATTACHED \\
DATA SHEET).
\end{tabular}

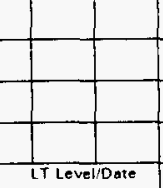

Level

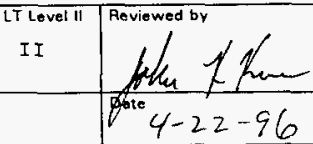

Att-2-2 
WHC-SD-TD-TRP-006, Rev. 0

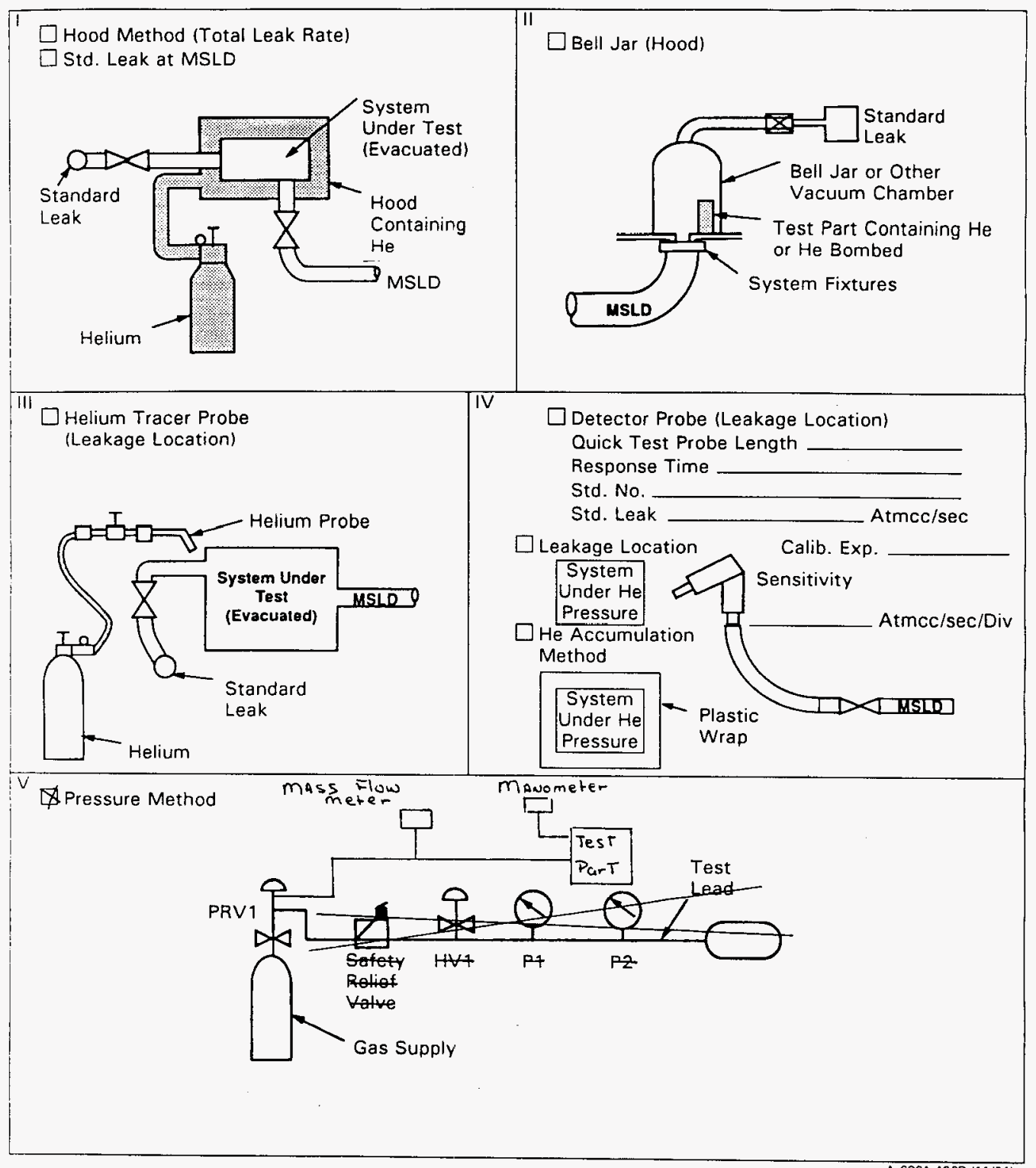




$$
\begin{array}{ll}
\text { WHC-SD-TD-TRP-006, Rev. } 0 \quad \text { Job No. } 96-25 \\
& 04|15 / 96+04| 16 / 96
\end{array}
$$

LOUP, HIGH_RESOLUTION STEREO VIDEO CAMERA SYSTEM

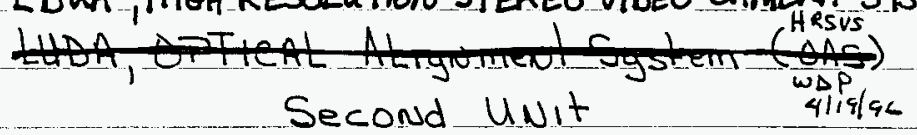

Manometer \#534-28-09-005, Exp. 03/12/99 - 0-10 _in. $\mathrm{H}_{2} \mathrm{O}$ MKS Flow Meter *679-28-03-024, Exp. 09108/96 0-10,000 lcm

Positive + Negative Pressure Tests of $7 \mathrm{in} . \mathrm{H}_{2} \mathrm{O}$ Appeared to cause NO DAMAGE.

LEAK RATE TEST

in. $\mathrm{H}_{2} \mathrm{O}$

1.0

2.0

2.5

3.0

4.0

5.0

6.0

7.0

1.0

2.0

2.5

3,0

4.0

5.0

6.0

7.0
Flow

$024 \times 10=240 \div 60=4.00 \mathrm{scc} / \mathrm{s}$

$043 \times 10=430 \div 60=7.20 \mathrm{scc} / \mathrm{s}$

$0.55 \times 10=550 \div 60=9.20 \mathrm{scc} / \mathrm{s}$

$0.58 \times 10=580 \div 60=9.70 \mathrm{scc} / \mathrm{s}$

$073 \times 10=730 \div 60=1216 \mathrm{sec} / \mathrm{s}$

$094 \times 10=940 \div 60=1566 \mathrm{scs} / \mathrm{s}$

$104 \times 10=1040 \div 60=17.331 \mathrm{scc} / \mathrm{s}$

$122 \times 10=1220^{\circ}=20=20.33 \mathrm{scc} / \mathrm{s}$.

$022 \times 10=220 \div 60=3.66$ sects

$043 \times 10=430 \div 60=7.16$ scots

$056 \times 10=560 \div 60=9.33$ seals

$057 \times 10=570 \div 60=9.50 \mathrm{ssc} / \mathrm{s}$

$073 \times 10=730 \div 60=12.16 \mathrm{scc} / \mathrm{s}$

$092 \times 10=920 \div 60=15.33 \mathrm{scc} / \mathrm{s}$

$101 \times 10=1010 \div 60=16.83$ sc as

$119 \times 10=\quad 1190 \div 60=19.83 \mathrm{scc} / \mathrm{s}$

Att -2-4 
WHC-SD-TD-TRP-006, Rev 0

\section{ATTACHMENT 3}

LABVIEW VIRTUAL INSTRUMENTS USED

DURIMG POST DELIVERY PROCEDURE

Att $-3-1$ 


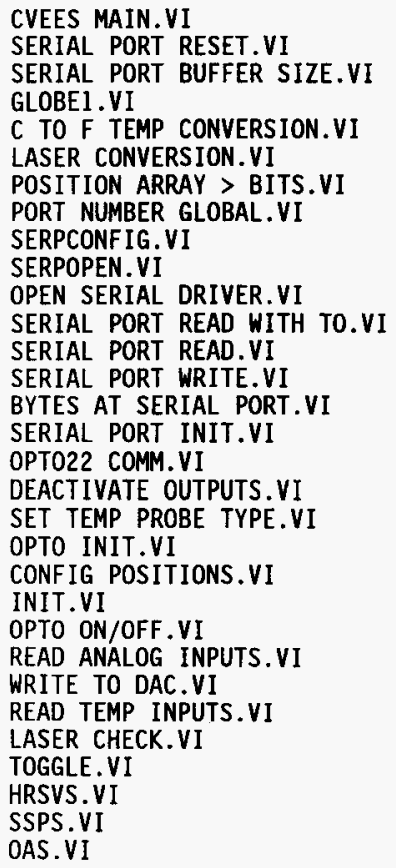

